Volume 2, Issue 2, April-June 2017, Pages: 162, DOI: http://dx.doi.org/10.19082/ah162

\title{
IRANIAN PRIMARY IMMUNODEFICIENCY REGISTRY (IPIDR)
}

Fatemeh Kiaee, Naeimeh Tavakolinia, Reza Yazdani, Gholamreza Azizi, Hassan Abolhassani, Asghar Aghamohammadi

Research Center for Immunodeficiencies, Pediatrics Center of Excellence, Children's Medical Center, Tehran University of Medical Science, Tehran, Iran

\section{Correspondence:}

Prof. Asghar Aghamohammadi, Tel: +982166428998, Fax: +982166923054, E-mail: ghamohammadi@sina.tums.ac.ir

\section{TYPE OF ARTICLE: CONFERENCE ABSTRACT}

\begin{abstract}
Introduction: Primary immunodeficiency diseases (PIDs) are a diverse group of genetic disorders which represent rare inborn errors of the immune system predisposing to recurrent infections, autoimmunity and malignancy. To achieve knowledge about the natural history of Iranian PIDs patients, we have established the central registry, entitled the Iranian Primary Immunodeficiency Registry (IPIDR).

Methods: In order to determine the disease burden of all types of PIDs and collect the clinical and laboratory data of these patients, data has been recorded on the basis of a clinical data questionnaires since 1999, and continues to the present day.

Results: In previous years, we published three reports of the Iranian Primary Immunodeficiency Registry (IPIDR). The first registry report was published in 2002 containing 440 PID patients, the second report was published in 2006 and included 930 patients (490 new cases), and third report was published in 2014 and consisted of 1,661(731 new cases) patients who registered during March 2006 through March 2013. By the last estimation in 2016, 2,021(360 new cases) patients were registered at the IPIDR. Notably, IPIDR has been nominated as a European Society for Immunodeficiencies (ESID) documenting center for registration of PID patients in Iran. Furthermore, Iranian Primary Immunodeficiency Network (IR PIN) (as a multidisciplinary organization dedicated to PID disorders) was established in 2016 to improve diagnosis of patients and collaboration between centers by the participation of all scientists and medical practitioners who are working on PIDs.

Conclusion: This registry system is used as a tool to show the prevalence and characteristics of different PIDs phenotypes and can also help to better identify novel disease-associated genes and subsequently new diagnostic and therapeutic strategies for PID patients.
\end{abstract}

KEYWORDS: IPIDR, PID, Registries

\footnotetext{
Abstracts of First National Congress of Medical Informatics, Mashhad, Iran, February 2017

(C) 2017 The Authors. This is an open access article under the terms of the Creative Commons Attribution-NonCommercialNoDerivs License, which permits use and distribution in any medium, provided the original work is properly cited, the use is non-commercial and no modifications or adaptations are made.
} 